\title{
EFFECT OF FOAM ROLLER AND STATIC STRETCHING ON BIOMECHANICAL PARAMETERS OF MUSCLE
}

\author{
Ugis Ciematnieks \\ Riga Stradiņš University, Latvia \\ Evita Tomanoviča \\ Riga Stradiṇš University, Latvia
}

\begin{abstract}
After training, it is needed to perform flexibility exercises for muscle stretching, but many choose to use the foam roller. With a foam roller, you can both exercise and perform a myofascial release that affects the deep tissues of extremities. Myofascial release improves blood circulation in muscle, develops elasticity, flexibility and minimizes the risk of an unwanted injury (Myers \& Frederick, 2012). Many studies are being carried out to determine the effects of the various types of stretching on balance, speed and reaction (Apostolopoulos, Metisos, Flouris, \& Koutedakis, 2015). Training programs are designed so that after applying different workloads at the end there is cool-down through stretching exercises, but these training plans rarely recommends foam rollers as stretching means, even though they are popular every day. Aim of study: Find out the most effective method for reducing muscle tension in lower extremities. The study identifies changes in the biomechanical parameters of the hamstring muscle group after general stretching exercises and foam roller, after GRIP fitness concept class, using the Myoton PRO biomechanical parameters measurement. The study do not show any significant differences that may be in favour of one or the other method. Literature sources indicate that foam rollers exercises helps to relieve and restore the strained muscles more quickly, increases flexibility (Barrett, 2017). Our study did not confirm any of such findings. Foam roller exercises for myophascial release is as effective as static stretching exercises.
\end{abstract}

Keywords: foam roller, muscle biomechanical parameters, stretching.

\section{Introduction}

Sufficient range of motion in the joints is needed for people to perform various physical exercises in their daily lives, doing everyday things. Nowadays, many different technologies are helping to do physical work, which causes people to move less and less, which also reduces flexibility, reduces range of motion. Stevens also points to a decrease in flexibility - people's lack of mobility contributes to a variety of health problems. Also, muscle tension can cause pain and discomfort (Stevens, 2013). Fitness training focuses on warm-up and cooldown stretching exercises. Many studies are being carried out to determine 
the effects of different applications of stretching on balance, speed and reaction (Apostolopoulos, Metisos, Flouris, \& Koutedakis, 2015). Training programs are designed so that after applying different loads at the end of the workout there is cooldown through stretch exercises, but foam rollers as muscle tension removers are rarely recommended. After training, it is needed to perform stretching exercises, but many athletes choose to use the foam roller (Barret, 2017). Benefits of foam roller:

- $\quad$ popular and easy to use;

- $\quad$ available in almost all sports clubs, fitness and physiotherapy studios;

- doesn't take a lot of space, lightweight.

With a foam roller it is possible to both exercise and perform a myofascial release, which affects the deep tissue of human body part. Myofascial release improves blood circulation in muscle, promotes mobility, flexibility, decreases stiffness caused risk of injury or trauma (Myers \& Frederick, 2012). However, the effectiveness of the application of foam roller after strength training for reducing the muscle strain of the lower limb remain uncertain.

The aim of the study: Possibility of static stretch exercise replacement with foam roller exercises with personal bodyweight.

Methods: The study included 20 female subjects aged 17 to 48 years (divided into two groups of 10 participants each) and 16 male subjects aged 19 to 48 years (divided into two groups with 8 participants in each). Each group performed a standard workout (a GRIP concept fitness class), after which one group performed static stretching, the other group was applying foam roller. Target area for stretching was upper part of lower extremities. Flexibility was determined by the Eurofit sit-and-reach test and muscle biomechanical parameters (muscle tone, elasticity, hardness and relaxation time) with a device for measuring muscle function MyotonPRO. Collected data was processed with descriptive statistics of MS Excel and IMB SPSS statistics v22.0.

\section{Literature review}

Flexibility is one of the motor abilities needed in daily life and sport. It is the ability to execute movements at full range of motion, by definition of American College of Sports Medicine (Parrott \& Xihe, 2013). Range of motion (ROM) shows the distance and direction in which the joint can be extended. This amplitude depends on the length of the muscle, the firmness of the connective tissue and the type of joint (Melzer, Schutz, Boulvain, \& Kayser, 2010). Flexibility can also be considered as the angle of motion in the human joint. The movements should not cause any pain, so it is important to stretch and provide flexibility in the joints to prevent unnecessary risk of injury (Schroeder, 2010). 
Flexibility can be divided into several types, which depend on how the muscles are stretched: static flexibility, ballistic flexibility, dynamic or functional flexibility, active and passive flexibility (Grasis \& Lubinska, 2015). Flexibility also helps the muscles recover faster, which provides future good performance, skills and good exercise techniques (Liguori, Dwyer, Fitts, \& Lewis, 2014). The joints are overloaded if the muscles are not stretched and the joints are numb. Overloading the joints can cause pain, which can create posture disorders. By stretching the tense muscles, the joints have the ability to regain mobility, which will prevent pain and incorrect posture. Increasing flexibility makes daily work and fitness tasks much easier and performance techniques are improved in any kind of sport (Thūls, 2006).

Benefits from flexibility and sufficient mobility: improving motor skills, movements, reducing the possibility of injuries, reducing back pain, reducing muscle pain, reducing muscle tension, reducing muscle tightness, stiffness, helps to relax, scar tissues (if any) regain their elasticity, improving metabolism, posture improvement, increasing concentration, decreasing obsolescence, reducing joint cartilage wear-down (Grasis \& Lubinska, 2015; Krauksts, 2006).

A study determined that static stretching proves as effective mean in treating hamstring strain than dynamic stretching. Comparing these two methods, static stretching is much more intensive, which also turns out to be better (Page, 2012). After stretching it would be possible to make increased movements with the target joint, as well as myofibrils retain their flexibility (Thūls, 2006).

Flexibility decreases with age as lifestyle tends to be calmer, more sedentary, and the amount of fluid in the tissues decreases. Flexibility is influenced by both the temperature of the external environment and the internal body temperature of the individual. It is possible to increase body temperature by warming up, thus increasing mobility and flexibility. Also, it is not recommended to stretch without warm up (Thūls, 2006).

Almost all soft tissues can be stretched - skin, fascia, tendon and ligament. The fascia will be stretched in any case, regardless of the stretching method used. Stretching the fascia has its benefits - it is possible to gain muscle lengthening, tissue is hydrated, connective tissue is stimulation (Myers, 2012). Myofascial stretching can stretch tendons, aponeuroses, and other dense fibrous connective tissues (Schleip, Duerselen, Vleeming, \& Naylor, 2012). Connective tissue responds differently because it depends on the type of stretching, density of connective tissue, location of tissue (Myers \& Frederick, 2012). Regularly and actively exercising, it would be advisable to do stretching exercises every day for several minutes each time to develop more flexibility and also maintain it at a good level (Grasis \& L,ubinska, 2015).

Foam rollers are popular among coaches and athletes in fitness all over the world as an exercising mean. The immediate effect is noticeable - the tense 
muscles are released, they recover much faster, and their elasticity increases (Barrett, 2017). The foam roller can be likened to a sports massage, but only an athlete can massage himself with the help of a roll - own body weight with the foam roller is used to massage problematic muscles and fascia, which at the same time increases mobility and helps the muscles to recover after exercise.

Miller did a study investigating whether the use of foam rollers increases elasticity in hamstrings compared to a control group who did not use them. In this study, it was found that using a foam roller for one minute on hamstrings for eight weeks significantly increased the elasticity of the hamstring (Miller \& Rockey, 2006).

The myotonometry method examines the principles of physiology and biomechanics in muscle. Physiological processes provide the required amount of blood in the tissues during activities, optimal blood plasma salts, and ions and provide the correct, appropriate protein content. From the biomechanical parameters of the muscle depends how these substances reach each biological tissue (Vain, 2002).

\section{Methodology}

The study included 36 participants, 20 female aged 17 to 48 years $(M=29.7$; $\mathrm{SD}=6.2)$ and 16 male aged 19 to 48 years $(\mathrm{M}=30.5 ; \mathrm{SD}=7.3)$. The females were divided into two groups - 10 women used a foam roller at the end of the workout, other 10 women applied a static stretching. Correspondingly, in the male group - 8 men applied foam roller and 8 men applied static stretching. Flexibility was determined by the Eurofit sit-and-reach motor ability test. The test can effectively determine the flexibility of the hamstring of the thigh. The results of the Eurofit test will be taken into account when comparing measurements, as indicator to compare which method (foam roller or static stretching) is more effective in relieving tension in the hamstrings.

We used a MyotonPRO device to measure the functional state of the muscles (muscle tone (expressed as frequency), elasticity (expressed as decrement coefficient), stiffness and relaxation time (shows a time a muscle takes to relax after mechanical stress). The myotonometry method examines the principles of physiology and biomechanics in muscle. Physiological processes provide the required amount of blood in the tissues during activities, optimal blood plasma salts, and ions and provide the correct, appropriate protein content. From the biomechanical parameters of the muscle depends how these substances reach each biological tissue (Vain, 2002). The concept class named GRIP was used as a standardized physical activity. The measurement process consisted of three parts per session: part 1 - The measurement was made before the concept lesson GRIP, with the respondent lying on the chest on fitness mat, trying to completely relax, 
then a biomechanical parameters of hamstring muscle was measured with a MYOTON PRO. Part 2 - reassessment after a GRIP lesson. Part 3 - each of the respondents applied one of the stretching methods that will remain the same throughout the study - myofascial release with foam roller or static stretching with holding a position. Each method included three exercises. These exercises was executed for three minutes in total, after which a hamstring muscle biomechanical parameters were measured again. At the beginning and end of the study, flexibility with the "sit and reach" test was determined.

\section{Research results}

During the study, in the first and last experimental class, each respondent was subjected to a Eurofit "sit-and-reach" test. Before a study mean measurement for the Eurofit test was $12.8 \mathrm{~cm}(+/-4.05)$ in females who had a foam roller method, while in the static stretching method $10 \mathrm{~cm}(+/-3.16)$. For male groups: with a foam roller method of $8.6 \mathrm{~cm}(+/-3.05)$, with a static stretching method of $0.4 \mathrm{~cm}(+/-0.13)$. At the end of the study, a Eurofit test was repeated when three GRIP concept classes were visited, and three times applied a stretching with foam roller and static stretching, accordingly. Results in "sit-and-reach" obtained for women: with a foam roller method $-16.5 \mathrm{~cm}(+/-5.22)$, with a static stretching method of $15 \mathrm{~cm}(+/-4.75)$, male results: with a foam roller method of $15.8 \mathrm{~cm}$ (+/-5.57), with a static stretching method of $7.9 \mathrm{~cm}(+/-2.8)$. Analyzing an obtained results, both female and male subjects have improved flexibility of the back of the body. For women performing foam roller exercises an improvement was in average $3.7 \mathrm{~cm}$, after static stretching exercises by $5 \mathrm{~cm}$. In the male group with a foam roller by $7.2 \mathrm{~cm}$ and with the application of the static stretching method by $7.5 \mathrm{~cm}$ (see table 1 ).

Table 1 Results in "sit-and-reach" test after applying stretching methods

\begin{tabular}{|c|c|c|c|c|c|c|}
\hline \multirow{2}{*}{ Gender } & $\begin{array}{c}\text { Stretching } \\
\text { method }\end{array}$ & $\mathbf{n}$ & $\begin{array}{c}\text { Before } \\
\text { stretching } \\
\mathbf{( c m} \pm \text { SD) }\end{array}$ & $\begin{array}{c}\text { After } \\
\text { stretching } \\
\text { (cm } \pm \text { SD) }\end{array}$ & P value & t-test \\
\hline \multirow{2}{*}{ Female } & Foam roller & 10 & $12.8 \pm 4.05$ & $16.50 \pm 5.22$ & \multirow{2}{*}{0.279} & -1.116 \\
\cline { 2 - 7 } Male & Static stretching & 10 & $10.00 \pm 3.16$ & $15.00 \pm 4.75$ & \\
\cline { 2 - 8 } & Foam roller & 8 & $8.60 \pm 3.05$ & $15.80 \pm 5.57$ & \multirow{2}{*}{0.807} & -0.249 \\
\hline
\end{tabular}


The MyotonPRO was used to measure changes in muscle biomechanical parameters during the study.

By studying the average frequency (tension) of all female, hamstring tension for left extremity before GRIP exercise was $12.84 \mathrm{~Hz}$ (foam roller group), for right extremity foam roller group before GRIP lessons was $12.88 \mathrm{~Hz}$; with static stretching group - left extremity $13.00 \mathrm{~Hz}$, right extremity $13.15 \mathrm{~Hz}$, which shows both legs have a normal muscle tone. Immediately after the GRIP exercise, the measurements of the hamstring tension are slightly lower than before the exercise: foam roller group - $12.78 \mathrm{~Hz}$ left, and $12.64 \mathrm{~Hz}$ for right extremity; static stretching group - left extremity $12.66 \mathrm{~Hz}$, right extremity $12.78 \mathrm{~Hz}$. The stress values during operation should be in the frequency range of 18 to $40 \mathrm{~Hz}$. This could only indicate that the GRIP class does not involve enough exercises for hamstring muscles. In the third measurement, after applying different stretching methods, the results did not differ significantly from those previously measured. Foam roller group - left extremity $12.75 \mathrm{~Hz}$, right extremity $12.65 \mathrm{~Hz}$, static stretching group - left extremity $12.85 \mathrm{~Hz}$, right extremity $12.55 \mathrm{~Hz}$. If there is no change in muscle frequencies during relaxation (resting state) and tension, then muscle function is considered impaired.

By studying the average muscle tone measurement of all male and comparing static stretching with foam roller, respondents who used static stretching had the higher muscle tone remaining after stretch method. Before GRIP concept class, the frequency values of muscle tone for a group using the foam roller method were $14.96 \mathrm{~Hz}$ for the left extremity and for right extremity $14.88 \mathrm{~Hz}$ (it indicates a normal muscle tone), after the GRIP concept class the tension in the left extremity for foam roller group was $14.82 \mathrm{~Hz}$, right extremity showed $15.26 \mathrm{~Hz}$, for static stretching group left extremity $15.40 \mathrm{~Hz}$, right extremity $15.37 \mathrm{~Hz}$, which is also still within normal range of muscle tone. Here are muscle tone results after two different stretching methods was applied - foam roller group left extremity $14.85 \mathrm{~Hz}$, right extremity $15.19 \mathrm{~Hz}$, static stretching group left extremity $15.81 \mathrm{~Hz}$, right extremity $15.51 \mathrm{~Hz}$. The results obtained did not show any significant difference between these three measurements.

\section{Conclusions and discussion}

Analyzing an outcome, the differences in the results obtained (sit-and-reach) in both groups (foam roller and static stretching) for both female ( $\mathrm{p}=0.279$, t-test -1.116 between foam roller and static stretch) and male ( $\mathrm{p}=0.807$, t-test -0.249 between foam roller and static stretch) groups are not significant and cannot demonstrate which method is better - foam roller or static stretching. There are several points how it can be explained:

- A larger number of participants may be needed to compare and better 
evaluate the study's measurements;

- In both gender groups, the minimum number of classes attended was 3, which may be too few times to make conclusions about the effectiveness of the stretching techniques used, be it myofascial release or static stretching. Several studies have shown the effect of a foam roller and myofascial release. There was study investigating whether the use of foam rollers increases elasticity in hamstrings compared to a control group who did not use them. This study found that applying a foam roller to hamstrings for one minute during eight weeks significantly increased the elasticity of the hamstrings (Miller \& Rockey, 2006);

- As one of the factors affecting results of study can be roll and stretch duration. There was three minutes given for each method and three exercises within this time. It is possible that using both methods would require a longer workout or more exercises, although the literature suggests that the exercise must be executed for at least 30 to 60 seconds (Krauksts, 2006). Miller also refers in his study to one minute of hamstring roll with foam roller (Miller \& Rockey, 2006);

- The concept of a GRIP concept class may not imply significant hypertension, so the roll and stretch effect is not significant.

During the study, at the first and last class, each respondent passed the Eurofit sit-and-reach test. Summarizing the results obtained, both female and male have improved test results after both stretching methods used. This may indicate that both methods are equally good for developing flexibility.

\section{References}

Apostolopoulos, N., Metisos, G., Flouris, A.D., \& Koutedakis, Y. (2015). The Relevance of Stretch Intensity and Position - a Systematic Review. Frontiers in Psychology, 6, 1128.

Barrett, S. (2017). Total Foam Rolling Techniques: Trade Secrets of a Personal Trainer. Bloomsbury Publishing Plc.

Grasis, N., \& Ļubinska, I. (2015). Lokanības attīstīšana. Trenera rokasgrāmata, Rīga, Jumava, 376.

Krauksts, V. (2006). Fiziskā sagatavotība. Kā to iegūt? Rīga, SIA Drukātava.

Liguori, G., Dwyer G.B., Fitts, T.C., \& Lewis, B. (2014). ACSM's Resources for the Health Fitness Specialist. Champaign, IL: Human Kinetics, 108. - 110.

Melzer, K., Schutz, Y., Boulvain, M., \& Kayser, B. (2010). Physical activity and pregnancy: cardiovascular adaptions, recommendations and pregnancy aoutcomes. Sports Med. 40(6), 493.

Miller, J.K., \& Rockey, A.M. (2006). Foam rollers show no increase in the flexibility of the hamstring muscle group. UW-L Journal of Undergraduate Research, 9, 1-4.

Myers, T., \& Frederick, C. (2012). Stretching and Fascia. In: Fascia: The Tensional Network of the Human Body. The Science and Clinical Applications un Manual and Movement 
Therapy (433 - 439). R. Schleip, T.W. Findley, L. Chaitow and P.A. Huijing, eds. Elsevier Ltd.

Page, P. (2012). Current Concepts in Muscle Stretching for Exercise and Rehabilitation. The International Journal of Sports Physical Therapy, 7(1), 109 - 119.

Parrott, J., \& Xihe, Z. (2013). A Critical View of Static Stretching and Its Relevance in Physical Education. Physical Educator, 70(4), 396.

Schleip, R., Duerselen, L., Vleeming, A., \& Naylor, I.L. (2012). Strain Hardening of Fascia: Static Stretching of Dense Fibrous Connective Tissues Can Induce a Tmporary Siffness Icrease Acompanied by Ehanced Matrix Hydration. Journal of Bodywork \& Movement Therapies, 16, 94-100.

Schroeder, J. (2010). Stretching. American Fitness, 28(3), 24., 26. - 27.

Stevens, K. (2013). Stretching into the 21st century; Part one. American Fitnesss, 16(1), 30. - 33.

Thūls, L. (2006). Treniņš visam k̦ermenim. Fiziskā sagatavotība, spēks, lokanība, psihologiskāa sagatavotība. Grāmatu apgāds Grafit.

Vain, A. (2002). Role of skeletal muscle tone and elasticity in the workability restoration of male cross-country skiers. Acta Academiae Olympique Estoniae, 10(1), 95-108. 